\title{
Juventude e Socialização Política: Atualizando o Debate ${ }^{1}$
}

\author{
Lucia Rabello de Castro ${ }^{2}$ \\ Universidade Federal do Rio de Janeiro
}

\begin{abstract}
RESUMO - O presente trabalho examina criticamente a atualidade da noção de socialização política, tendo em vista as questões que hoje se colocam sobre o distanciamento dos jovens em relação à política. O conceito de socialização política é analisado sob dois aspectos principais: em primeiro lugar, são discutidos seus pressupostos relacionados a uma teoria identitária de subjetividade que essencializa posições subjetivas relacionadas à idade, e se apoia numa visão desenvolvimentista da trajetória de vida humana. Em segundo lugar, discute-se como os estudos de socialização política pressupõem uma divisão entre espaços público e privado, em que as relações de transmissão cultural entre jovens e adultos, restritas ao espaço privado, desconsideram a contribuição da juventude em relação às decisões da vida em comum.
\end{abstract}

Palavras-chave: socialização política; juventude; relações intergeracionais; subjetividade.

\section{Youth and Political Socialization: Up-Dating the Debate}

\begin{abstract}
The present work analyses from a critical point of view the notion of political socialization and its current issues about the distancing of youth in relation to politics. The political socialization concept is analyzed according to two main aspects: first, it is discussed its assumptions in relation to an identity theory of subjectivity that essentializes subjective positions related to age, and it is based on a developmental perspective on human trajectory. Second, it is discussed how political socialization studies presuppose a division between public and private spaces, where the relations of intergenerational transmission are restricted to the private space, and thus, do not take into account youth contribution to the decisions of collective life.
\end{abstract}

Keywords: political socialization; youth; intergenerational relationships; subjectivity.

Política e juventude apresentam-se como temas distantes em boa parte da literatura sobre jovens, ao passo que temáticas como, por exemplo, sexualidade, identidade, relações com pares e questões ligadas à vocação profissional, têm sido frequentes na produção de trabalhos sobre a juventude. $\mathrm{O}$ fato de que os jovens, até atingirem sua maioridade, estão alijados de direitos políticos plenos na maioria das sociedades modernas, contribui para que a reflexão sobre Política e juventude tenha sido significativa apenas no tocante a como os jovens se preparam para a atividade política na idade adulta. Não somente na Psicologia, como também em outras áreas do conhecimento, os jovens constituem foco de interesse enquanto passíveis de serem ensinados a adotarem atitudes e condutas que são consideradas importantes nas democracias modernas. A articulação entre juventude e Política tem sido entendida, principalmente, por meio do conceito de socialização política, ou seja, o processo de preparação do jovem para assumir seu lugar ulterior de cidadão, consciente de seus direitos e deveres políticos.

O objetivo deste trabalho é examinar a atualidade do conceito de socialização política a partir de problemas que são levantados hoje sobre as relações entre a juventude e a

1 O presente trabalho é versão modificada da conferência "A socialização política de jovens: a preparação para a ação (política) se faz pela ação?", proferida no IV Simpósio Brasileiro de Psicologia Política, Belo Horizonte, setembro 2006. Agradeço ao CNPQ e FAPERJ pelo apoio na elaboração deste trabalho.

2 Endereço para correspondência: Av. Pasteur 250, $2^{\circ}$ andar - Pavilhão Nilton Campos. Rio de Janeiro, RJ. CEP 22290-240. Tel/fax: (21) 22953208.E-mail: 1rcastro@infolink.com.br.
Política. Especialistas e leigos assustam-se com o declínio dos ‘valores políticos' entre os jovens, observando atitudes de apatia, indiferença e descrédito em relação à política institucionalizada que poriam em cheque o futuro das democracias, e atestariam o afastamento do cidadão comum das decisões sobre o destino das sociedades (O'Toole, Lister, Marsh, Jones \& McDonagh, 2003; Putnam, 2000; Stolle \& Hooghe, 2004; Welti, 2002). Impõe-se, assim, uma aproximação entre juventude e Política pela via de uma 'crise' que se observaria entre os jovens — ainda que não apenas nesse segmento em relação à manutenção das democracias, já que, para que essas vigorem, é necessário que haja mobilização e investimento por parte dos grupos e dos indivíduos para garantir a vitalidade das instituições que lhes dão sustentação.

Neste trabalho, examino criticamente o conceito de socialização política, tal como aparece nos estudos seminais sobre essa temática (Dawson \& Prewitt, 1969; Easton \& Dennis, 1969; Greenstein, 1965; Hess \& Torney, 1967; Hyman, 1959), e também naqueles mais recentes, alguns oriundos da Psicologia, outros da Sociologia e da Ciência Política, que têm, de modo geral, se fundamentado em um modo específico de articular juventude à política, qual seja, pela via de um processo propedêutico. Significa, outrossim, considerar a juventude como uma etapa preparatória para a vida política plena na idade adulta e, nesse sentido, pressupõe-se uma teoria da subjetividade juvenil como ainda não pronta para o exercício pleno da vida cívica, ou ainda no processo de desenvolver capacidades e atitudes que podem favorecer a experiência democrática ulterior. $\mathrm{O}$ conceito de socialização política ilumina justamente o processo de 
preparação dos jovens frente a assumir e exercer a atividade política conforme os modos convencionais e estabelecidos pelas gerações anteriores (Dekker, 1996; Fendrich \& Turner, 1989; Niemi \& Hepburn, 1995). Estipulam-se, assim, pontos de chegada e resultados - desiderata do processo de socialização política, teleologicamente direcionados a formar 'adultos políticos' com determinados perfis subjetivos. O exame crítico da noção de socialização política resulta em aproximar os campos da juventude e da Política, não pela via da socialização, mas por outra perspectiva teórica sobre a produção da subjetividade juvenil, que não a pautada pelo desenvolvimento/progresso individual, de modo a poder considerar a contribuição juvenil aos destinos da sociedade como um valor do momento presente.

Ao problematizar o conceito de 'socialização política' espero, outrossim, desconstruir a articulação da política à juventude por meio da socialização, deslocando o debate para questões que hoje adquirem relevância, a saber: como os próprios jovens representam a atividade política institucionalizada, como se vêem fazendo política ou sendo políticos, como articulam sua existência ao político e à política. Por isso mesmo, a problematização do conceito de socialização política dos jovens pode ser fecunda no sentido de aproximar de forma diferente juventude e Política no contemporâneo, época em que a Política não parece interpelar os jovens como atividade criadora e transformadora do mundo. Nessa linha, aposta-se na fecundidade que possa ser gerada, justamente, pela 'crise da política', por seu desencantamento e, daí, pela interrogação que se impõe a respeito de que novas formas a atividade política pode se revestir, e ter ainda algum sentido.

Ponho em questão dois aspectos. Em primeiro lugar, a perspectiva identitária que caracteriza o modo de produção de subjetividade no processo de socialização, pressupõe um sujeito que 'amadurece' para a atividade política. Essa atividade demanda determinadas capacidades ou atributos de personalidade considerados como pré-condições psicológicas para o exercício da política. O trabalho de Döbert, Habermas e Nunner-Winkler (1987), por exemplo, postula a aquisição de determinadas capacidades como a do diálogo racional, do descentramento cognitivo, da independência do juízo para o exercício e a participação nas decisões políticas.

Em segundo lugar, problematizo a delimitação inequívoca entre o domínio público e o privado que o conceito de socialização pressupõe. Socializar-se, como o termo indica, significa se preparar para a inserção nas redes sociais mais amplas, nas quais as trocas estão regidas, não pelos códigos familiares, mas pelas normas acordadas no domínio público. Portanto, a socialização indica o processo que tem lugar aquém do domínio público, no privado do lar, onde crianças e jovens se preparam para alcançar sua condição plena de cidadãos. A socialização está para o privado, assim como o exercício da política está para o público, pois é apenas no espaço da convivência comum dos cidadãos que se pode falar, pensar e agir politicamente. Nesse sentido, a noção de socialização (de crianças e jovens) significou atribuir-lhes uma condição ainda não totalmente adequada para a vida em grupo, e, portanto, circunscreveu o domínio de sua ação ao privado, ou ao que não é, e não pode ser político, ou na melhor das hipóteses, o que ainda é pré-político.

\section{Socialização Política: Moratória para a Ação Política}

"Socialização" é uma noção cara aos estudos na área da juventude e da infância como um todo, e diz respeito aos processos de aquisição de habilidades e atitudes que credenciam determinado sujeito ao exercício ulterior de uma função ou atividade (Jahoda, 1996).

A relação entre socialização política e juventude parece inicialmente tácita. Afinal, parece uma obviedade que política e juventude só se articulem pelo fato de que os jovens ainda não estejam completamente preparados para a atividade política, e sua participação política esteja condicionada a um processo de credenciamento. Portanto, o conceito de 'socialização política' indica, num primeiro plano, o processo de preparação ou habilitação que se faz necessário para que os jovens possam participar da atividade política.

A literatura sobre socialização política emerge com vigor na década de 60 do século passado, na América do Norte, no ambiente de questões suscitadas pela Segunda Guerra Mundial, quando as pesquisas investiram sobre as origens das motivações e dos comportamentos políticos. Na atmosfera intelectual do pós-guerra tornou-se importante investigar os antecedentes de personalidade do cidadão comum que concorriam para a formação de atitudes de preconceito, racismo ou xenofobia. Sears e Levy (2003), em artigo recente, interpretam o volume de pesquisas sobre socialização política da época como a tentativa de cientistas sociais de tradição liberal de prevenir males políticos tais como, o etnocentrismo, a opressão das maiorias e o genocídio, "por meio de melhores experiências de socialização" (p. 60). Os trabalhos seminais de David Easton e Robert Hess na Universidade de Chicago, e Fred Greenstein, em Yale, apontam a importância do conceito de socialização política para a análise dos sistemas políticos, sua manutenção e mudança. Easton e Hess (1962) mostram, por exemplo, como as orientações políticas transmitidas na infância adquirem resistência à mudança, e "como cada nova geração emerge na cena política como uma tabula rasa, do ponto de vista político, sobre quem o sistema político deve deixar suas marcas" (p. 232). Parece que, desse modo, assegura-se mais a estabilidade do sistema do que suas possibilidades de mudança, e sobretudo, maximizam-se os efeitos da transmissão geracional por se tratar de crianças, cuja condição de dependência e vulnerabilidade as conduz a idealizar as figuras de autoridade (Easton, 1968).

Dois aspectos são dignos de nota. Em primeiro lugar, a importância fundamental que as pesquisas acima mencionadas atribuíram às experiências que acontecem na infância e adolescência, tomadas como momentos "altamente impressionáveis" (Sears \& Levy, 2003, p. 62). Desse modo, o desenvolvimento de atitudes políticas desejáveis dependeriam do tipo de interações que uma criança teria no cotidiano de sua vida familiar (Greenstein, 1965; Jennings \& Niemi, 1968; Niemi \& Sobieszek, 1977), como também na escola (Ehman, 1980). Tais experiências, por ocorrerem nesse momento de vulnerabilidade psicológica, teriam um impacto mais profundo, e, portanto, torna-se-iam fundamentais para determinar as atitudes do futuro adulto. Em segundo lugar, essas pesquisas colocavam a criança e o jovem como recipientes passivos dos estímulos ambientais e do que os adultos desejavam fazer 
deles. A teoria de sujeito psicológico esposada por essa tradição de investigação supunha uma correspondência desejável entre as atitudes do indivíduo (como adulto e cidadão) e as demandas do sistema.

A noção de socialização empregada nesses trabalhos desenvolveu-se na tradição sociológica funcionalista (Parsons, 1964) em que, por meio do processo de internalização (Berger \& Luckmann, 1961), os indivíduos aprendem as condutas prescritas e demandadas pelo sistema social, os chamados papéis sociais, gerados na gestão entre as motivações individuais e as normas prescritas pelas posições sociais. A internalização converte o indivíduo em ator social, ou seja, personagem social cuja subjetividade, ao longo de seu desenvolvimento e socialização, é o lado reverso do sistema social. Em maior ou menor grau, as teorias sobre a socialização se referem ao processo em que o sistema social tem assegurado seu funcionamento e sua reprodução na medida em que os indivíduos desenvolvem atitudes, normas, comportamentos e valores adequados aos seus papéis sociais, mesmo se admitindo que alguma defasagem possa ocorrer na correspondência entre a subjetividade dos indivíduos e a objetividade do sistema. Desde esse ponto de vista, as teorias da socialização visam responder as seguintes questões: como a sociedade funciona? como se mantém integrada? como se assegura sua reprodução? A partir dessas preocupações, torna-se fundamental saber como os indivíduos adquirem suas pautas de conduta colimadas aos fins sociais. As variáveis da personalidade individual nos estudos de socialização política (Jennings \& Niemi, 1968; Krampen, 2000; Niemi, 1973) ilustram, justamente, a necessidade de se avaliar o impacto subjetivo das demandas do sistema na formação do indivíduo apto ao regime democrático.

Em estudos brasileiros recentes sobre socialização política, a tradição de pesquisa sobre socialização política é reinvestida, ainda que adquira conotações contemporâneas. A discussão toma o rumo de responder à preocupação de como o individualismo, o consumismo e a globalização, dentre outros aspectos, apresentam riscos para as democracias modernas, no sentido de enfraquecerem seu 'capital social', considerado como o 'equipamento subjetivo sentimental e atitudinal' dos indivíduos que se julga fundamental para a vida democrática. Na esteira dos estudos de Putnam sobre capital social, Baquero e Baquero (2007), Baquero (2003), Lucas (2003), Nazzari (2005), Schmidt (2000), Silveira e Amorim, (2005) compreendem a condição juvenil como propícia à formação de valores, atitudes e consciência cidadã necessários à vida cívica. Poder avaliar o potencial e as predisposições juvenis para o associacionismo, a cooperação e a solidariedade permite dimensionar o quanto uma sociedade acumula para a consolidação dos valores democráticos e a confiança nas suas instituições. Nazzari, em estudo com jovens de duas cidades do Paraná, observa que o processo de socialização política vigente não estaria favorecendo bons níveis de confiança, cooperação e participação grupal nos jovens, predispondoos a "desenvolverem atitudes de apatia e indiferença", e "não os incentivando a sentimentos e comportamentos relacionados à importância da frequência de participação em atividades associativas e políticas" (p.153, grifos nossos). Segundo a autora, a socialização política se direciona para uma finalidade bastante clara, que é a de conduzir os jovens a adquirirem comportamentos e atitudes que se reconhecem como politicamente relevantes.

Baquero (2003) também discute a importância dos fatores subjetivos na democracia. A preocupação consiste em "estimular e motivar os cidadãos a participar politicamente", "dar poder aos cidadãos aumentando sua capacidade colaborativa" (pp. 83-4), como também criar hábitos de cooperação e solidariedade pelo processo de socialização. $\mathrm{O}$ investimento educacional na juventude deve, segundo esse autor, atentar para uma educação para a democracia, na contra-corrente à erosão dos laços sociais e à desconfiança do setor público. $\mathrm{O}$ conceito de capital social diz respeito ao mecanismo, que em tempos de descrédito da política, pode estabelecer mediações entre o cotidiano das interações sociais e o campo da política, aquilatando o nível de confiança e de solidariedade nas relações sociais e a participação nas associações.

No entanto, o conceito de socialização política tem sido criticado em outros estudos. Buckingham (2000), em obra que analisa a formação de cidadãos em um mundo de comunicação de massa televisiva, propõe uma visada para além da socialização. $\mathrm{O}$ autor se baseia em estudos anteriores (e.g., Ichilov, 1990) que criticam a perspectiva conservadora das teorias de socialização, ao enfatizarem a reprodução daquelas orientações e condutas políticas, nas crianças e nos jovens, que os adultos podem reconhecer como válidas. Essas orientações e condutas são passíveis de se tornarem obsoletas face às rápidas transformações do mundo de hoje. Buckingham afirma a importância dos posicionamentos que crianças e jovens assumem em relação a outros grupos sociais nos espaços públicos. Para ele, o papel de telespectador coloca o jovem na posição de definir e construir sentidos em relação a atores dominantes, como governo e políticos, por exemplo, o que indica que os jovens estabelecem, de pronto, sentidos do que vem a ser cidadão, mesmo que sua ação no espaço público não esteja legitimada. Em veia diferente, mas também crítica, Machado (1979) argumenta que os estudos de socialização política sobre-enfatizam a estabilidade política e a reprodução social, desconsiderando possibilidades de formação de uma contracultura política. Nesse sentido, parece problemático enfocar a juventude apenas como etapa moratória da cidadania, tendo em vista sua adequação ao sistema político vigente, pois se descartam as possibilidades de considerar as contraforças e contraposicões que ela pode mobilizar.

A noção de socialização responde à preocupação com a manutenção da sociedade cujos fins de integração implicam na evolução do indivíduo rumo ao seu adequado desempenho social. Algumas teorias psicológicas, sobretudo aquelas que se apoiam no conceito de desenvolvimento individual, têm servido de base à discussão sobre as relações entre sistemaator em que, de modo geral, o sujeito é visto como produto de sua socialização (Dubet \& Martucelli, 1997). A preocupação em explicar o funcionamento e a integração da sociedade ensejou, desde a adoção de uma concepção hipersocializada dos indivíduos (Wrong, 1961), até a postulação de teorias da subjetividade em que o subjetivo é sempre o resultado de um processo de aquisição social (Dubet \& Martucelli, 1997), se contrapondo ao social como uma dimensão oposta. Além disso, tomou-se a política como fato (e não como convicção; Rancière, 2007) ao circunscrevê-la como aspecto que, de 
fato, só acontece tão somente na vida adulta, de modo que na juventude e na infância só poderiam ser observadas as origens e formações iniciais — 'proto-atitudes' — da vida cívica ulterior. Mesmo considerando que uma visão mais recente sobre a socialização reconheça o papel ativo e produtor que as crianças e os jovens assumem nos processos de transmissão cultural, de forma geral, a ênfase do conceito permanece nas aptidões que devem aparecer no final do processo (Jennigs, Stoker \& Bowers, 1999), e como essa aptidão corresponde ao funcionamento do que já está instituído — a sociedade dos adultos e suas instituições.

\section{A Política como o Campo da Diferença e da Contradição}

A perspectiva da socialização pressupõe uma determinada concepção do processo de subjetivação em que o trajeto biográfico está balizado por pontos de partida e pontos de chegada ao longo do qual o indivíduo está sujeito a um processo de transformação, seja por práticas sociais formais de ensino-aprendizagem, seja por processos familiares que deixam marcas originais para futuras ações e atitudes.

Num artigo seminal em que revisa o conceito de socialização na Sociologia, Alanen (1987) lembra que ao retratar a sociedade como um fato externo aos indivíduos, Durkheim cunhou o termo socialização para se referir ao determinismo social que circunstancia a vida dos indivíduos na direção de um sentido moral, qual seja, o de uma superação da 'nãocivilização’ em prol do acordo social e da civilização. Do lado da 'não-civilização' foram colocadas as crianças, como também os jovens. Socializar-se significava, no contexto durkheiminiano, a inexorável sujeição do indivíduo ao fim social pactuado nas normas e valores societários. Do ponto de vista do indivíduo jovem, a ele é atribuída a tarefa de ultrapassar sua condição presente, deixando para trás a condição de ser jovem para poder "se desenvolver" e se tornar, enfim, um adulto (Castro, 2001). A socialização enfatiza para o jovem a perspectiva de futuro quando o alcance da maturidade acontece junto com a introjeção da norma civilizada.

Nesse sentido, como também ressalta Alanen (1987), uma superavaliação do produto, em detrimento do processo, passou a caracterizar o entendimento da socialização. $\mathrm{O}$ conceito de socialização permaneceu distante de uma visão que pudesse considerar os aspectos caóticos, contraditórios e inconsistentes do processo de se tornar adulto. Esse conceito passou a ser gradualmente enfocado a partir de seus resultados que expressariam a convergência funcional entre os aspectos individuais, a serem adquiridos por parte das crianças e dos jovens, e as demandas da sociedade de adultos, a ser reproduzida.

O que está em jogo, embora oculto, nesse processo é certamente um embate, uma luta, cujo resultado é bastante previsível em função da posição de poder dos adultos em relação a jovens e crianças. Ao longo do processo de socialização, a maioria dos aspectos que tenderiam para a dispersão, e não eram comensuráveis com as demandas instituídas e os fins acordados, seriam necessariamente invisibilizados, descartados e negativizados. Nessa acepção, o processo de socialização, ao integrar a criança e o jovem ao todo social, "desperdiçou" possibilidades de reinvenção do laço social que não estivessem previamente acordadas, estabelecidas e previstas. Portanto, a agenda das mudanças favorecidas pelas práticas socializantes se afastou de direções não previsíveis de transformação societária (mesmo considerando que essas direções não tenham sido totalmente abolidas - até porque crianças e jovens, por mais convergente e reconciliada que se considere a relação entre sujeito e todo social, não se convertem em máquinas cujo output está necessariamente previsto pelo input.).

A teoria de subjetividade juvenil nos estudos de socialização política retrata os jovens como sujeitos ainda não sociais, como também, sujeitos ainda não políticos (ou prépolíticos), opondo, em campos distintos, duas configurações identitárias: ou se é jovem/criança, ou se é adulto. Crianças e jovens não são nunca adultos, e estes, por sua vez, não são nunca jovens ou crianças.

Tal perspectiva propiciou que se legitimasse a invisibilização social e política dessas categorias sociais, enquadrando-as como atores pré-políticos, cujo processo de desenvolvimento passou a ser controlado rumo ao perfil unívoco de uma identidade adulta. O sentido de comparação, pressuposto na visão de desenvolvimento psicológico, aponta um ponto de chegada que é utilizado invariavelmente para medir as diferenças resultantes entre o ponto de chegada e qualquer outro ponto da trajetória, mantendo inquestionável a direção do processo: ou seja, jovens e crianças são sempre comparados aos adultos no sentido de se avaliar negativamente suas diferenças em relação aos últimos. Consequentemente, aqueles traços, valores, virtudes e comportamentos relevantes ao processo político instituído deveriam ser adquiridos e internalizados, e não quaisquer outros. Alguns estudos chegam até a recomendar a necessidade de intervenções desenvolvimentais precoces (Krampen, 2000), de modo a prevenir tipos extremos de adultos desinteressados politicamente. Ou seja, o que se visa é prevenir e controlar o desenvolvimento de modo que um determinado perfil político de adulto seja produzido. Morss (1996), na sua crítica mordaz à estratégia de comparar momentos diferentes do curso de vida humana, afirma ironicamente que é a lógica do superior falando com o inferior. Seria, por exemplo, o adulto falando ao jovem: "eu estou na sua frente, por isso sou seu superior" (p. 150).

É na tradição feminista que vamos encontrar a crítica mais virulenta à visão de um sujeito identitário que informa o ideal de sujeito político presente na grande parte dos estudos de socialização política. Cavarero (1992), Mouffe (1993) e James (1992), dentre inúmeros outros autores, apontam que o modelo do cidadão nas comunidades políticas modernas inspira-se, desde sempre, naquele do homem livre e racional que informa e fundamenta o paradigma de uma subjetividade neutra, não-sexuada e universalizada. Mais ainda, supõe-se um sujeito capaz de decisão autônoma e independente, que se pense falando por si, e cujo processo de subjetivação resulte numa separação psicológica clara entre o eu e o outro. $\mathrm{O}$ próprio modelo de tomada de decisão democrática faz valer, principalmente nas teorias liberais, a visão recorrente de um sujeito capaz de comunicação racional, que por meio da argumentação participa da busca do consenso.

No entanto, como colocou Young (2000), a argumentação racional, pura e simples, delimita um modo particular 
de se expressar, de validar opiniões, de se posicionar frente ao outro e de compreender o mundo, característico de um subgrupo historicamente constituído, e que co-existe, com outras inúmeras formas de diálogo e de construção de si e do outro. Assumindo-se a argumentação racional como o modelo de diálogo e tomada de decisão no processo político, universaliza-se o ideal de sujeito implícito nesse modelo, que é justamente daquele indivíduo que se credencia para participar da comunidade política.

A crítica feminista desconstruiu o sujeito idêntico e uno considerado como efeito histórico das relações de dominação masculina. Falar do(a) ator(a) político(a), nessa veia, significa poder acolher aquilo que é excluído quando se preconiza um sujeito político universal, auto-centrado, racional e independente. O que ficou de fora nesse processo foi justamente o jovem/a criança: politicamente não pronto, 'imaturo' do ponto de vista jurídico e invisível para efeito de reconhecimento social. A construção do sujeito idêntico a si mesmo, uno e unívoco - $\mathrm{o}$ adulto, só pôde acontecer pelo delineamento do que foi deixado de fora, do que não foi incluído, ou seja, do que não é igual ao adulto modelar.

Por outro lado, abrir mão da concepção identitária significa, em termos teóricos, admitir uma subjetividade que é dividida (eu e outro, eu e aquilo que supostamente é estranho e diferente), dotada de razão e des-razão. Subjetividade que se produz precariamente, já que a identidade (o ser igual a si mesmo) só pode ser compreendida a partir de seu par dialético que é a diferença (Dews, 1996). A diferença não apenas contorna de fora a unidade do que é idêntico, ou ainda, não apenas define o que a constitui dialeticamente (Adorno, 1944/1995), mas, sobretudo, consiste no que resiste ou excede o fechamento da identidade. Nesse sentido, a identidade não é: ela se constitui permanentemente não sendo, não podendo definir-se de forma unívoca, porque é permanentemente desestabilizada pela diferença (que pode constituir uma ameaça para a identidade). Identidade e diferença constituem um campo de tensão e de contradição na constituição da subjetividade. A identidade se supõe fixa e pretende manter a diferença sob controle (Honig, 1993), como forma de defesa do que pode vir a desorganizá-la, tendo em vista que a diferença seria o aspecto que mina a totalidade e a univocidade da identidade, a "fenda" que a torna susceptível de incompletude e transformação. Portanto, ser idêntico e igual a si mesmo seria apenas uma ficção, já que o estranho, o que é não-eu também faz parte do que sou; assim como o outro não é o domínio da diferença, do que não é. Identidade e diferença apresentam-se como um par de oposições que caracterizam os processos de subjetivação humana e de construção da alteridade. Portanto, a identidade precisa da diferença.

Apreender essas contribuições no âmbito da socialização política significa admitir uma relação constitutiva entre adulto e jovem, pois ambos não se constituem como mônadas fechadas - um 'sendo', de um lado, e o outro 'não sendo'. Na concepção identitária da subjetividade, o jovem tem sido definido como o 'fora', o 'que ainda não é' em relação ao adulto; este pode, então, se manter seguro, coeso e pronto. Os atributos e qualidades que qualificavam o adulto para o processo político lhe pertenciam, como características próprias. Ao mesmo tempo, qualquer adulto poderia se credenciar, em princípio, ao espaço de discussão e decisão políticas, já que todos teriam as qualificações para o debate racional, ou, como colocou Habermas (1984), 'o uso público da razão'. O jovem e a criança delimitam o campo da alteridade que deve ser excluída no devir racionalista do adulto. A subjetividade 'limpa' e 'lisa' do adulto racional ejeta no outro da criança e do jovem o que pode ser fonte de turbulência, conflito, aspereza e engano: sejam outras formas de pensar, sentir ou construir a realidade, sejam outras maneiras de dialogar que não estejam apoiadas na argumentação racional. $\mathrm{O}$ desideratum seria que o processo político pudesse se tornar também 'limpo' e 'liso', levado adiante sob forma do diálogo, e finalizado quando o 'melhor argumento vence', quando o consenso, então, pode se estabelecer.

Nessa visão idealizada do processo político, crianças e jovens encarnam os atores não qualificados que trazem vicissitudes imprevisíveis ao processo político: como chegar, por exemplo, ao consenso quando os atores partem de distintas concepções de mundo, e se utilizam de códigos de comunicação variados e múltiplos? As contradições do processo político parecem se exacerbar, ou se explicitar, quando subjetividades distintas daquela expressa pelo modelo do adulto racional são cogitadas de participar do processo.

As implicações seriam no sentido de desvelar a política como o campo que é também atravessado pela contradição constitutiva, e não pela linearidade; pelo imprevisível e não pela previsibilidade, pelo embate e não pelo consenso. Nesse sentido, não parece haver ponto de chegada no processo político, assim como não haveria na trajetória humana. Assim como a democracia se situa como o ponto do horizonte que sempre se afasta à medida que dele tentamos nos aproximar (Mouffe, 2005), também o processo político se constitui na insolúvel indeterminação que não se resolve e nem se totaliza no consenso; do mesmo modo, jovens e adultos perfazem alternâncias de possibilidades subjetivas, constituindo-se mutuamente.

Nessa perspectiva, os encontros entre adultos e jovens assumem múltiplas funções; porém, em algumas situações, tais encontros podem engendrar conflitos e contraforças, potencializando um momentum político, uma vez que este se qualifica com os dissensos e conflitos gerados nas situações em que se decide para onde vamos ou o que queremos, como coletividade. A política não seria uma atividade resultado do credenciamento em que alguns podem participar e outros não, mas o processo que se constitui quando subjetividades diferentes/estranhas umas às outras, ou ainda inimigas, têm que se escutar e produzir acordos precários para a convivência. Como coloca Honig (1996), inspirando-se em Arendt (1986), nenhuma classe de pessoas deve estar excluída da ação política, mas a política pode estar protegida de desejos e necessidades que seriam mais cabíveis no âmbito privado, porque aí, "é a vida que está em jogo, e não o mundo" (p. 260).

\section{Potencializando Politicamente as Relações entre Adultos e Jovens}

Os estudos sobre socialização política reiteram a divisão entre público e privado como dois âmbitos essencialmente 
distintos. Mais do que isso: qualificam todos os encontros intergeracionais (entre adultos e jovens/crianças) como sem relevância pública, i.e., sem relevância para o que se constitui como nosso destino comum. Se a socialização política diz respeito aos processos que ocorrem no âmbito privado de preparação do jovem para seu exercício político no âmbito público, ela considerou as relações educacionais (na escola, por exemplo) como atos que não interessam necessariamente a todos, ou seja, atos não públicos. Bignotto (2002) ressalta que:

a definição da esfera pública e da esfera privada é na verdade o traçado de uma fronteira entre as diversas atividades que compõem a vida humana. Essa definição implica escolher entre os atos que interessam a todos e aqueles que são o reflexo dos interesses dos individuos ou grupos isolados. (p. 287, grifos meus)

A casa e a escola foram considerados como espaços pré-políticos, ou apolíticos, articulados à sobrevivência e aos códigos e normas estabelecidas pelo parentesco, ou às prerrogativas que uns detêm sobre os outros ao possuírem a delegação da transmissão de valores e das normas societárias. O interesse de grande parte dos estudos sobre socialização política focalizou como as crenças e valores das figuras parentais são assimilados pelos jovens que irão atuar no âmbito público num momento ulterior (Finchilescu \& Dawes, 1998; Flanagan \& Sherrod, 1998; Plutzer, 2002). Destaca-se, nesse sentido, o interesse na reprodução cognitiva entre as gerações como aspecto importante para a estabilidade e a reprodução societárias.

A direção desses estudos sobrevaloriza dois aspectos: em primeiro lugar, a reafirmação das crenças e dos valores professados e instituídos, e em segundo lugar, o sentido unívoco da transmissão geracional em que a geração dos mais velhos modela o comportamento e as atitudes dos mais novos, os quais são considerados como os que apenas recebem o legado geracional (Percheron \& Jennings, 1981; Tedin, 1974). A transmissão geracional, o próprio termo ressalta, conduz de uma geração à outra a 'acumulação do humano' (Agamben, 1978/2005), que deve ser guardada pelos mais velhos e reproduzida pelos mais novos.

Assim, os estudos de socialização política afirmam, implicitamente, uma preocupação preponderante na reprodução societária, que é garantida por meio da adequação vigilante e do controle sobre os processos de transmissão geracional. Impõe-se como aspecto prevalente o legado que deve ser preservado e assimilado pelos mais novos. $\mathrm{O}$ que a geração mais nova pode acrescentar, modificar ou recusar ao longo do processo de transmissão geracional se considera, frequentemente, como 'crise', 'gap' geracional, ou então, permanece invisível como desgaste do próprio processo. Embora a retórica das gerações mais velhas admita as novidades que as novas gerações podem trazer à construção societária, de fato, os jovens não estão na posição de iguais cujas demandas podem ser legitimamente expressas, discutidas e reconhecidas (Castro, 2006).

Por outro lado, a crise geracional hoje aponta para a necessidade de se questionar se a transmissão tem que ter uma direção unívoca de cima para baixo, ou seja, do adulto, como iniciador, para o jovem, como destinatário, e nesse sentido, qual a legitimidade de se posicionar as novas gerações apenas como destinatárias da herança cultural. Resta saber se a transmissão cultural não pode ser pensada como um processo que se realiza de forma mais horizontal, privilegiando a demanda de cada indivíduo, e portanto, que desnaturaliza posições fixas, seja de destinatário ou remetente. Cabe às gerações mais velhas também 'aprender' com as gerações mais novas, e aí reside a importância de incluí-las efetivamente no campo interlocutório, tornando efetivas suas formas de participação política. Para tal, seria necessário respeitar a importância de sua voz, não apenas retórica e paternalisticamente, mas de forma radical.

Ao delimitar o lugar da nova geração no âmbito do privado (na família e na escola), suas ações ficaram desautorizadas de qualquer alcance coletivo e público porque, de fato, ela não era vista nem como iniciadora de algum processo social importante, nem como quem poderia trazer inovações societárias que devessem ser levadas a sério. Sua contribuição era aguardada para o momento da maioridade etária quando, então, ela poderia se tornar visível e legítima do ponto de vista político. Nessa perspectiva, os estudos sobre juventude e política focalizaram o alinhamento dos jovens com os valores cívicos considerados importantes, ou as atitudes prototípicas que poderiam contribuir mais tarde para a reprodução institucional, e não, exatamente, o que eles pensam, dizem e fazem no agora para transformar e melhorar suas vidas. A reticência em dar voz aos jovens, como também às crianças, encontra ressonância na dificuldade de se enfrentar o desafio de, ao mesmo tempo em que se preservam valores e normas societárias, poder dar lugar ao que ainda não é conhecido, ao que é larvar no processo societário, sempre acompanhado de incertezas, angústias e turbulências.

Nesse sentido, a subjetivação política de jovens permaneceu esvaziada e despotencializada, delimitada ao exercício vicário de replicação do que já existe. O 'novo', o ‘imprevisível' que poderia acometer a relação intergeracional e dar lugar aos embates na relação entre diferentes permaneceu, na maior parte das vezes, recusado ou negado. Resulta que a transmissão geracional não pôde se constituir como um momento potencialmente político entre os adultos e os mais novos, na medida em que a posição putativa dos mais novos como sujeitos ainda não políticos, qualificou, de antemão, sua fala como restrita à ordem do privado, por conseguinte, fala que ainda não alcançou importância social e política, e portanto, não pode ser incluída como contribuição à construção de como e para onde vivemos e caminhamos.

Nas últimas décadas, vemos um cenário que se modifica a partir do redesenho dos espaços privados e públicos. Os acordos entre as gerações baseados na sujeição da geração mais nova por força do sentido do dever, da gratidão e da autoridade para com os mais velhos se esvaem sacudidos pelas mudanças vertiginosas de uma sociedade tecnocrática que pouco ou nada quer dever ao passado e aos antecedentes. Tanto na família, como na escola, ou seja, nos espaços em que se privatizou a relação entre adultos e jovens, entram em agonia as bases pelas quais se assegurava a reciprocidade geracional e, portanto, a reprodução institucional (Monteiro, 2008). Dito de modo esquemático, os jovens não parecem querer aprender com os mais velhos, mas, também, os adultos 
continuam aferrados à posição hegemonicamente estabelecida. A noção de crise geracional parece demasiado fraca para dar conta do abismo que caracteriza os novos contornos das relações geracionais no contemporâneo. Para quem trabalha com jovens e pode sentir mais proximamente a dimensão do problema, a 'crise' hoje dá sinais de uma revolução sem nome, sem armas e sem ideologia, em que o que outrora garantia o laço geracional, hoje não assegura mais a reciprocidade da convivência entre as gerações.

A disseminação dessa crise extrapola o âmbito privado das trocas geracionais atingindo o âmbito público. Pode-se, com alguma razão supor que a tão alardeada descrença, ou o suposto afastamento da política por parte dos jovens reverbera justamente essa precarização dos acordos entre as gerações, sentidos mais agudamente nos espaços ditos privados, mas que afetam o espaço público e o destino comum. Essa crise 'privatizada', referenciada principalmente aos espaços da família e da escola, estaria, a nosso ver, apontando na direção de trazer a público - publicizar - a questão da educação, como aspecto que diz respeito a todos pela sua importância de selar nosso destino comum. E, sobretudo, tal embate geracional implicaria em repactuar o lugar do jovem nas decisões sobre sua vida e seu futuro, suas relações com os mais velhos e com a sociedade em geral. Nesse sentido, a 'crise geracional' pode estar favorecendo o momento político de redefinir novas condições de igualdade nas relações entre adultos e jovens, assim como verificar se tais condições de igualdade geram outros lugares sociais possíveis para os jovens (Rancière, 2007). Por exemplo, qual a cidadania cabível a jovens e crianças? Quais seriam as respostas (responsabilidades) de uma cidadania jovem?

Cabe, então, indagar: como restabelecer o pacto geracional tendo em vista esse outro pacto, o da convivência humana mais ampla? E, em vista de tal projeto, como decidir sobre o que deve ser preservado na herança humana acumulada? E o que deve ser modificado? E como?

São essas, a nosso ver, as questões que surgem como emblemáticas no contemporâneo, demandando que se reflita sobre as démarches entre adultos e jovens que sempre oportunizam a criação de novas questões e novos espaços. Não seriam esses os momentos onde outras possíveis questões públicas podem ser produzidas e apresentadas? Nesse sentido, uma divisão rígida entre espaço privado e espaço público, e aquela que diz quem está ou não autorizado a transitar nesse último, deixa de ser interessante para transformar a ordem social vigente na direção de uma maior equidade entre as gerações. Assim, não caberia privatizar as falas e as ações da geração mais nova, como se essas tivessem que aguardar a maioridade para terem algum impacto e sentido público. Um novo momentum político se oportuniza, ao se considerar que o espaço público pode acolher e abrigar outras experiências de emancipação ainda não conhecidas e que, portanto, não podemos antecipar. Incluir os segmentos sociais que foram tidos como, 'por natureza', não capacitados para refletir e discutir sobre o que vai mal, ou o que é injusto, pode significar se abrir para experiências de renovação da ação política. Se é verdade, como muitos afirmam, que os jovens hoje não querem aprender nada com ninguém, e parecem tudo saber, parece ser também verdade que eles não estejam na posição de nada saber.
O conceito de socialização política parece ser insuficiente, ao não dar conta das demandas de renovação da sociedade, e também da política, tal como essa última tem sido até agora exercida pelos adultos. Os jovens subjetivam-se politicamente além da escola e da família, e por meio de práticas não antecipadas, como suas experiências na cidade (Castro, 2004), culturais e artísticas (Holloway, 2005; Norris, 2002; Paes, 2006; Pleyers, 2005). Além disso, o produto da socialização política - o adulto afeito e interessado em participar de longe, e, ocasionalmente, do processo político - parece estar cada dia mais envolto na nebulosa da desconfiança da política, no nojo dos políticos e no fervor do seu bem-estar pessoal.

As ações dos jovens no cenário urbano reivindicam outras formas de participação social e política por meio do estabelecimento de coletivos cuja marca parece ser a mobilização das paixões e dos afetos (Ion \& Ravon, 1998). Recentemente, advertiu Mouffe (2005) que as teorias políticas correntes, ao enfatizarem o cálculo racional de interesses ou a deliberação baseada em critérios racionais, esqueceram que os afetos são uma das mais poderosas forças que movem os sujeitos no campo da política. São eles, eu acrescentaria, que concorrem para que os indivíduos busquem e negociem identificações coletivas que fornecem as bases para as ações compartilhadas. Um outro cenário público se desenha, onde os atores juvenis configuram a participação política e a própria noção de política. Essa é criticada por estar delimitada a um espetáculo formal, abstrato e distante do mundo da existência cotidiana, com seus problemas e suas tensões. As lutas juvenis por visibilidade rebatem para a política convencional e para os políticos, que 'já era' o jogo político cujo único fim se assenta sobre a reprodução societária, tout court; esse jogo, perdido na sua processualidade, e alheio a uma visão compartilhada sobre o destino comum que mobilize todos, adultos e jovens, tem passado ao largo do que os jovens desejam e procuram.

\section{Considerações Finais}

Para finalizar, gostaria de trazer a afirmação de Eagleton (2000) que, ao discutir a questão do político no contemporâneo, diz que "a melhor preparação para a ação política é a ação política" (p. 76). Significa, na nossa discussão sobre socialização política de jovens, que os pressupostos de uma propedêutica de jovens e crianças para a política não responde a demandas atuais porque elimina 'o político' da experiência de transmissão geracional. Encarada como algo da ordem do privado, e dirigida para manter a reprodução societária, a transmissão geracional exclui qualquer sentido de emancipação que essa experiência possa conter.

Na perspectiva de uma dinâmica geracional emancipatória, questionamos o conceito de socialização política, e apontamos para o sentido público que as relações entre adultos e jovens podem, e devem, ter na medida em que alcançam importância para o traçado de nosso destino comum, hoje mais do que antes. A crise geracional contemporânea denota, mais do que uma fragilidade na gramática de transmissão entre gerações, um questionamento amplo a respeito da tradição e de seus valores, das instituições e, consequentemente, dos 
lugares sociais atribuídos aos atores sociais convencionais. O lugar do jovem frente ao adulto transformou-se em virtude da multiplicidade de posições subjetivas que ambos passaram a ocupar, e tais posições foram desatreladas da continuidade e sequência ordenada do trajeto linear que caracterizava a história biográfica. Ser jovem, hoje, não encerra apenas a preparação para, um dia, ser adulto, mas a vivência de possibilidades subjetivas e estruturais condizentes com esse momento da vida. Aí reside, também, a singular contribuição da juventude à sociedade como um todo.

Por outro lado, as relações educacionais que, por razões históricas e culturais, se estabeleceram no âmbito da esfera privada, e portanto, limitadas em termos de relevância política, são atravessadas, hoje, por novos questionamentos, como aquele que indaga sobre a não participação do jovem no diálogo e nas decisões a respeito de quais conhecimentos e experiências podem lhe ser úteis no presente e no futuro. Ou seja, parece que a inclusão do jovem como sujeito de sua história, da construção de si e do mundo em que vive se impõe frente aos desafios do mundo contemporâneo. Um deles é justamente poder redesenhar as formas do fazer político que hoje se atêm às da política como governabilidade. A preocupação com a juventude e seu afastamento e indiferença em relação à política instituída mostram, justamente, como não somente o jovem, mas o cidadão comum, está distante das questões comuns que atingem a todos, delegadas aos políticos profissionais. Buscar outros caminhos que tornem os jovens, e os indivíduos em geral, concernidos com as questões da coletividade passa por uma reinvenção da política. Nesse sentido, as relações entre adultos e jovens, principalmente na escola, ganham importância porque podem iniciar, em um espaço não regido pelas relações de parentesco, embates emancipatórios em que valores como a igualdade, a justiça e a liberdade se tornem aspectos a serem pautados, testados e vividos.

Em tempos em que a política não parece fazer sentido para os jovens, a reconstrução da política, entendida como 'aquela atividade que reinventa o social' (Laclau, 1994) torna-se um imperativo. Acompanhar e trazer à luz tal processo significa aproximar juventude e política, não por via do conceito de socialização, mas antes de tudo, pela via de uma desconstrução que permita avaliar posições e lugares sociais na cadeia geracional, e examinar criticamente como e porquê as relações entre adultos e jovens parecem limitadas em seu potencial emancipatório.

\section{Referências}

Adorno, T. (1995). A dialética do esclarecimento (G. A. Almeida, Trad.). Rio de Janeiro: Zahar. (Trabalho original publicado em 1944)

Agamben, G. (2005). História e infância: destruição da experiência e origem da história (H. Burigo, Trad.). Belo Horizonte: Editora UFMG. (Trabalho original publicado em 1978)

Alanen, L. (1987). Growing up in the modern family. Rethinking socialization, the family and childhood. Em K. Ekberg \& P. Mjaavatn (Orgs.), Growing into a modern world (pp. 919-945). Trondheim: The Norwegian Centre for Child Research,
Arendt, H. (1986). A condição humana. Rio de Janeiro: Forense.

Baquero, M. (2003). Construindo uma outra sociedade: o capital social na estruturação de uma cultura política participativa no Brasil. Revista de Sociologia Politica, 21, 83-108.

Baquero, M., \& Baquero, R. (2007). Educando para a democracia: valores democráticos partilhados por jovens portoalegrenses. Ciências Sociais em Perspectiva, 6, 139-153.

Berger, P., \& Luckmann, T. (1961). The social construction of reality: A treatise in the sociology of knowledge. New York: Doubleday.

Bignotto, N. (2002). Entre o público e o privado: aspectos do debate ético contemporâneo. Em I. Domingues, P. R. Margutti-Pinto \& R. Duarte (Orgs.), Ética, política e cultura (pp. 281-298). Belo Horizonte: Editora UFMG.

Buckingham, D. (2000). The making of citizens: Young people, news \& politics. Londres: Routledge.

Castro, L. R. (2001). Da invisibilidade à ação: crianças e jovens na construção da cultura. Em L. R. Castro (Org.), Crianças e jovens na construção da cultura (pp. 19-46). Rio de Janeiro: $\mathrm{Nau} /$ Faperj.

Castro, L. R. (2004). A aventura urbana. Rio de Janeiro: 7 Letras/Faperj.

Castro, L. R. (2006). Admirável mundo novo: a cadeia das gerações e as transformações do contemporâneo. Em D. Dalbosco, D. Colinvaux \& L. Banks (Orgs.), Psicologia do desenvolvimento: reflexões e práticas atuais (pp. 249-268). São Paulo: Casa do Psicólogo.

Cavarero, A. (1992). Equality and sexual difference: Amnesia in political thought. Em G. Bock \& S. James (Orgs.), Beyond citizenship equality \& feminist politics: Difference female subjectivity (pp. 32-47). Londres: Routledge.

Dawson, R., \& Prewitt, K. (1969). Political socialization. Boston: Little, Brown \& Co.

Dekker, H. (1996). Democratic citizen competence: Politicalpsychological and political socialization research perspectives. Em R. Farnen (Org.), Democracy, socialization and conflicting loyalties in East and West: Cross-national and comparative perspectives (pp. 386-410). New York: St Martin's Press.

Dews, P. (1996). Adorno, pós-estruturalismo e a crítica da identidade. Em S. Zizek (Org.), Um mapa da ideologia (pp. 51-70). Rio de Janeiro: Contraponto.

Döbert, R., Habermas, J., \& Nunner- Winkler, G. (1987). The development of the self. Em J. M. Broughton (Org.), Critical theories of psychological development (pp. 275-299). New York: Plenum Press.

Dubet, F., \& Martucelli, D. (1997). A socialização e a formação escolar. Lua Nova, 40/41, 242-266.

Eagleton, T. (2000). The idea of culture. Londres: Sage.

Easton, D. (1968). The theoretical relevance of political socialization. Canadian Journal of Political Science, 1, 125-146.

Easton, D., \& Dennis, J. (1969). Children in the political system. New York: McGraw Hill.

Easton, D., \& Hess, R. (1962). The child's political world. Midwest Journal of Political Science, 6, 229-246.

Ehman, L. (1980). The American school in the political socialization process. Review of Educational Research, 50, 99119.

Fendrich, J., \& Turner, R. (1989). The transition from student to adult politics. Social Forces, 67, 1049-1057. 
Finchilescu, G. \& Dawes, A. (1998). Catapulted into democracy: South African adolescents' sociopolitical orientations following rapid social change. Journal of Social Issues, 54, 563-583.

Flanagan, C., \& Sherrod, L. (1998). Youth political development: An introduction. Journal of Social Issues, 54, 447-456.

Greenstein, F. (1965). Children and politics. New Haven: Yale University Press.

Habermas, J. (1984). The theory of communicative action. Cambridge: Polity.

Hess, R., \& Torney, J. (1967). The development of political attitudes in children. Garden City, NY: Doubleday.

Holloway, J. (2005). Change the World without taking power: The meaning of revolution today. Londres: Pluto Press.

Honig, B. (1993). Political theory and the displacement of politics. New York: Cornell University Press.

Hyman, H. H. (1959). Political socialization. Glencoe, IL: Free Press.

Ichilov, O. (1990). Political socialization, citizenship education and democracy. New York: Teachers College Press.

Ion, J., \& Ravon, B. (1998). Causes publiques, affranchissement des appartenances et engagement personnel. Lien Social et Politiques-RIAC, 39, 59-71.

Jahoda, M. (1996). Socialização. Em W. Outhwaite \& T. Bottomore (Orgs.), Dicionário do pensamento social do século XX (pp. 710-712). Rio de Janeiro: Zahar.

James, S. (1992). The good-enough citizen: Citizenship and independence. Em G. Bock \& S. James (Orgs.), Beyond citizenship equality \& feminist politics: Difference female subjectivity (pp. 4865). Londres: Routledge.

Jennings, M. K., \& Niemi, R. (1968). The transmission of political values from parent to child. American Political Science Review, 62, 169-184.

Jennings, M. K., Stoker, L., \& Bowers, J. (1999). Politics across generations: Family transmission reexamined [relatório 2001-15]. Berkeley: Institute of Governmental Studies.

Krampen, G. (2000). Transition of adolescent political action orientations to voting behavior in early adulthood in view of a social-cognitive action theory model of personality. Political Psychology, 21, 277-297.

Laclau, E. (1994). Introduction. Em Laclau, E. (Org.), The making of political identities (pp. 1-10). Londres: Verso.

Lucas, J. I. P. (2003). Juventude e antipolitica no Brasil: um estudo de cultura política e ideologia. Tese de Doutorado, Universidade Federal do Rio Grande do Sul, Porto Alegre..

Machado, M. (1979). Ciência política e socialização política nos Estados Unidos. Revista Dados, 22, 65-73.

Monteiro, M. (2008). Convivência e participação: fios e desafios da educação na contemporaneidade. Uma experiência no cotidiano de uma escola pública da Baixada Fluminense. Tese de Doutorado, Universidade Federal do Rio de Janeiro, Rio de Janeiro.

Morss, J. (1996). Growing critical. Alternatives to developmental psychology. Londres: Routledge.

Mouffe, C. (1993). The return of the political. Londres: Verso.

Mouffe, C. (2005). On the political. Londres: Routledge.

Nazzari, R. K. (2005). Capital social e socialização política dos jovens no Brasil. Educação Unisinos, 9, 145-154.

Niemi, R., \& Hepburn, M. (1995). The rebirth of political socialization. Perspectives on Political Science, 24, 7-16.
Niemi, R., \& Sobieszek, B. (1977). Political socialization. Annual Review of Sociology, 3, 209-233.

Norris, P. (2002). Democratic phoenix: Reinventing political activism. New York: Cambridge University Press.

O’ Toole, T., Lister, M., Marsh, D., Jones, S., \& McDonagh, A. (2003). Tuning out or left out? Participation and non-partiicpation among young people. Contemporary Politics, 9, 45-61.

Paes, J. M. (2006). As múltiplas 'caras' da cidadania. Em L. R. Castro \& J. Correa (Orgs.), Juventude contemporânea: perspectivas nacionais e internacionais (pp. 107-134). Rio de Janeiro: Nau/ Faperj.

Parsons, T. (1964). Social structure and personaliy. New York: Free Press.

Percheron, A., \& Jennings, M. K. (1981). Political continuities in French families. A new perspective on an old controversy. Comparative Politics, 13, 421-436.

Pleyers, G. (2005). Young people and alter-globalisation: From disillusionment to a new culture of political participation. Em J. Forbrig (Org.), Revisiting youth political participation (pp. 133144). Strasbourg: Council of Europe Publishing.

Plutzer, E. (2002). Becoming a habitual voter: Inertia, resources and growth in young adulthood. American Political Science Review, 96, 41-56.

Putnam, R. (2000). Bowling alone: The collapse and revival of American community. New York: Simon and Schuster.

Rancière, J (2007). On the shores of politics. Londres: Verso.

Schmidt, J.P. (2000). Juventude e politica nos anos 90: um estudo de socialização política. Tese de Doutorado, Universidade Federal do Rio Grande do Sul, Porto Alegre.

Sears, D., \& Levy, S. (2003). Childhood and adult political development. Em D. Sears, L. Huddy \& R. Jervis (Orgs.), Oxford handbook of political socialization (pp. 60-109). Oxford: Oxford University Press.

Silveira, A., \& Amorim, M.S. (2005). Socialização política e capital social: uma análise da participação da juventude no contexto escolar e político. Educação Unisinos, 9, 155-163.

Stolle, D., \& Hooghe, M. (2004). Inaccurate, exceptional, onesided or irrelevant? The debate about the alleged decline of social capital and civic engagement in Western societies. British Journal of Political Science, 35, 149-167.

Tedin, K. (1974). The influence of parents on the political attitudes of adolescents. American Political Science Review, 68, 1579-1592.

Young, I. M. (2002). Inclusion and democracy. Oxford: Oxford University Press

Welti, C. (2002), Adolescentes in Latin America: Facing the future with skepticism. Em B. Brown, B. Larson, R. \& Saraswathi, T. (Orgs.), The world's youth: Adolescence in eight regions of the globe (pp. 276-306). Cambridge: Cambridge Univ. Press.

Wrong, D. (1961). The over-socialized conception of man in modern sociology. American Sociological Review, xxvi, 183-193.

Recebido em 12.02.08 Primeira decisão editorial em 05.04.09 Versão final em 07.05.09 Aceito em 15.06.09 